\title{
REVIEW
}

Open Access

\section{Mapping the role of digital health technologies in the case detection, management, and treatment outcomes of neglected tropical diseases: a scoping review}

Binyam Tilahun ${ }^{1 \dagger}$, Kassahun Dessie Gashu' $^{1}$ Zeleke Abebaw Mekonnen ${ }^{1,2}$, Berhanu Fikadie Endehabtu ${ }^{1}$ and Dessie Abebaw Angaw ${ }^{2,3^{*}+}$ (1)

\begin{abstract}
Background: Neglected tropical diseases (NTDs) are a diverse group of communicable diseases that principally impact the world's poorest people. The use of digital health technologies is an emerging and promising way to improve disease prevention, diagnosis, case detection, treatment delivery, and patient follow-up and facilitating health facility appointments thereby improving health outcomes. While the growing implementation of digital health technologies is evident, there is a lack of comprehensive evidence on the impact of digital health technologies in the control of NTDs. The main objective of this review was to map different pieces of evidence on the use of digital health technologies for case detection, management, and treatment outcome of the neglected tropical diseases.

Methods: We conducted a scoping review guided by the Joanna Briggs Institute guidelines. The studies were searched using electronic databases like MEDLINE (PubMed), Science Direct, Cochrane Library, and manual searching engines. Two authors extracted the data and compared the results. Discrepancies were resolved by discussion or the third reviewer made the decision. We produced the distribution of geographical locations, residents (setting), types of publications, and digital health technologies used on neglected tropical diseases using tables and graphs.

(Continued on next page)
\end{abstract}

\footnotetext{
* Correspondence: dessieabebaw96@gmail.com

${ }^{\dagger}$ Binyam Tilahun and Dessie Abebaw Angaw contributed equally to this work.

${ }^{2}$ Health System Directorate, Ministry of Health, Addis Ababa, Ethiopia

${ }^{3}$ Department of Epidemiology and Biostatistics, Institute of Public Health, College of Medicine and Health Science, University of Gondar, Gondar,

Ethiopia

Full list of author information is available at the end of the article
}

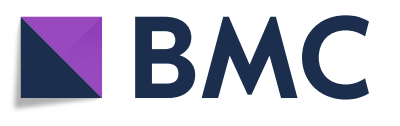

(c) The Author(s). 2021 Open Access This article is licensed under a Creative Commons Attribution 4.0 International License, which permits use, sharing, adaptation, distribution and reproduction in any medium or format, as long as you give appropriate credit to the original author(s) and the source, provide a link to the Creative Commons licence, and indicate if changes were made. The images or other third party material in this article are included in the article's Creative Commons licence, unless indicated otherwise in a credit line to the material. If material is not included in the article's Creative Commons licence and your intended use is not permitted by statutory regulation or exceeds the permitted use, you will need to obtain permission directly from the copyright holder. To view a copy of this licence, visit http://creativecommons.org/licenses/by/4.0/. 


\begin{abstract}
(Continued from previous page)
Findings: A total of 996 potentially relevant studies were generated from the initial search, and six studies were found to satisfy all the inclusion criteria and included in the final review. The review found that telehealth, eHealth, $\mathrm{mHealth}$, telemedicine, and electronic health record were used digital health technologies to assess their impact on case detection, disease management, and treatment outcome of neglected tropical diseases. Mobile health was a feasible digital health technology for lymphatic filariasis patient identification and mHealth, eHealth, and electronic health records found to improve the service access, outcomes, and monitoring of visceral leishmaniasis at the community health system.

Conclusion: The scoping review identified that there were limited studies to see the impact of digital health technologies on case detection, management, and treatment outcomes for neglected tropical diseases. We also found that digital health technologies like ehealth, electronic medical linkage, telemed, and telehealth were practicable for patient identification, for treatment and diagnosis through contact with health professionals and teleconsultation, and support in improving health service delivery at the community-health system for managing the disease in both rural and urban settings.
\end{abstract}

Keywords: Neglected tropical diseases, Digital health technologies, Case detection, Disease management, Treatment outcome

\section{Background}

The neglected tropical diseases (NTDs) are a diverse group of communicable diseases that prevail in tropical and subtropical conditions in 149 countries that causes substantial illness for more than 1.5 billion of the poorest, most marginalized communities worldwide with devastating health, social, and economic consequences [1-3]. The most common neglected tropical diseases are Protozoan infections (human African trypanosomiasis, Chagas disease, and leishmaniasis), helminthic infections (ascariasis, trichuriasis, schistosmiasis, lymphatic filariasis, onchocerchiasis, and dracunculiasis), bacterial infections (Buruli ulcer, leprosy, and trachoma), and viral infection (rabies and dengue) with high endemicity in the developing countries [4-6].

According to a $2010 \mathrm{WHO}$ report, neglected tropical diseases have traditionally ranked low on national and international health agendas and cause massive but hidden and silent suffering, and frequently kill the poor people [7]. NTD has many consequences like impairs physical and cognitive development, contribute to mother and child illness and death, limit productivity, and entire communities become mired in poverty as disabled and unemployed people struggle to afford food and basic services, including healthcare [8-12].

According to the World Health Organization (WHO) road map for neglected tropical diseases 2021-2030, lack of timely access to affordable treatment leaves hundreds of millions severely disabled, disfigured, or debilitated, often resulting in social exclusion, stigmatization, and discrimination [3]. Even though morbidity and mortality due to NTDs were underestimated as long-term disabilities [4, 13-15], the combined burden of disease due to NTDs has been estimated at 56.6 DALYs, compared with malaria at 46.5 and tuberculosis (TB) at $34.7[4,7]$.
The World Health Organization (WHO) recommends five public-health strategies for the prevention and control of NTDs: preventive chemotherapy; intensified casemanagement; vector control; the provision of safe water, sanitation, and hygiene; and veterinary public health [7]. Although strategies to control and eliminate NTDs primarily for human African trypanosomiasis, leishmaniasis, soil-transmitted helimintiasis (STH), Chagas disease, trachoma, schistosmiasis, and onchocerchiasis are available, ultimately, success will almost certainly depend on access to new and cost-effective products for improved control [1].

Currently WHO recommended for low and middleincome countries to develop non-laboratory-based diagnosis and controlling policies with low-cost ways to prevent, diagnose, and treat the diseases [16]. Additionally, the use of electronic technologies like mobile phone message/reminder, ehealth, mhealth, and medical health records facilitates education and awareness, remote data collection, remote monitoring, communication and training of healthcare providers, monitoring of disease and epidemic outbreaks, and diagnostic and treatment support [16-18].

Digital health technologies are devices used for computing platforms, facilitate connectivity (create network) and sensors for healthcare and related issues and mostly used by healthcare providers [19]. It is an emerging and promising way to improve disease prevention, diagnosis, treatment compliance, medication adherence, and honoring clinic appointments thereby enhancing health outcomes $[20,21]$. A report from the agency for healthcare research and quality revealed that incorporating electronic technology in health for disease management efforts can yield significant cost savings for patients and providers [22, 23]. A review study in 2015 on the use of 
Telemedicine technologies in the management of infectious diseases indicated that patients with infectious and non-infectious diseases who are receiving telemedicine care report feeling more satisfied with and more involved in their care. Furthermore, patients claimed that attending remote appointments through telemedicine saved their time, diminished the distance traveled, and reduced missed workdays [24, 25].

While the growing popularity of digital health technologies is evident, and promoters are eager to demonstrate their effect on NTDs diagnosis and case finding and detection, disease management, and treatment outcome impact may be overlooked in low- and middleincome countries; people may have poor access to quality healthcare due to poor road networks, long-distance travel, lack of trained or skilled health professionals, lack of health facilities, and ignoring the disease [26, 27]. As a result of this, challenges and the potential importance of digital health technologies for improving access for healthcare; the technology could be applied on NTDs detection, management, and treatment outcome to people living hard to reach areas. We performed scoping review other than systematic review due to not miss many papers, for instance, expertise view and case report studies. In systematic review, quality of the study could be assessed weather the study is eligible or not to be incorporated in the review; whereas in scoping review, assessing the quality of the study is optional [28]. This review builds the evidence base of digital health technologies by updating previous studies and assessing a broad range of finding from usability to impact on outcomes of neglected tropical diseases. Therefore, this review aims to map evidence of digital health technologies on neglected tropical diseases detection, management, and treatment outcome of the diseases.

\section{Methods}

Our review aimed to map the available evidence on the role of digital health technologies like electronics health record, eHealth, electronic medical records, electronic community linkage, mHealth for case detection and case finding, loss to follow-up control, and disease management of NTDs. This review was conducted within the Reporting Items for Systematic Reviews and MetaAnalyses extension for Scoping Reviews (PRISMA-ScR) checklist [29] and it was guided by Joanna Briggs Institute (JBI) scoping review guidance [28].

\section{The scope review research question}

We used a Population, Concept, and Context (PCC) framework developed by the Joanna Briggs Institute to determine the eligibility of our primary research question [28]. The following is the primary research question: what are the available pieces of evidence of digital health technologies applied for case detection, disease management, and treatment output for neglected tropical diseases in the world?

\section{Eligibility criteria}

Studies were included based on the following criteria: (1) Studies that reported evidence on the application of digital health technologies for one of the neglected tropical disease affected patients used for treatment support, (2) studies that report the application of one of the digital health technologies either for disease management or lost to follow-up control among one of the NTD patients, (3) articles that report a piece of evidence on the application of one of the digital health technologies for case detection, management, and treatment output, (4) pieces of evidence of digital health technologies on treatment support and lost to follow-up control from systematic reviews, meta-analyses, letters. Whereas, articles reported only evidence on the importance of digital health technologies were excluded.

\section{Data sources and searching strategies}

The studies were searched using electronic databases like MEDLINE (PubMed), CINAHL with full-text via EBSCOhost, and green FILE; Science Direct; Cochrane Library; and Google Scholar advanced databases. Other data sources like Hinari and Google were used to search for studies. In this electronic database search, Medical Subject Headings (MeSH) were used for database searching and Boolean terms (AND/OR) were used to separate our keywords. The following keywords were used: "neglected tropical disease," leishmaniasis, Schistosomiasis, Elephantiasis, trachoma, Dracunculiasis, "Soiltransmitted Helminths," Onchocerciasis, "Chagas Disease," dengue fever," "Human African Trypanosomiasis," Telemedicine, telemed, mobile health, Telehealth, eHealth, mHealth, "Computerized Medical Record"," "Electronic Health Record," "Electronic Medical Record" (medical record, computerize), "Record Linkage," Medical, "treatment outcome," "Patient-Relevant Outcome," "Rehabilitation Outcome," "Treatment Effectiveness," "Treatment Efficacy," lost to follow-up, "Dis management," "case finding," "case detection." Additional relevant articles were identified by searching the reference lists of full-text articles studies published from conception to the last searched date of August 02, 2020, were included (Additional file 1).

\section{Study selection and reliability}

We performed initial searches by two review authors with extensive experience in systematic reviews. Screening of titles, abstracts, and full texts was conducted independently by two review authors (DA and KD). A disagreement regarding the decision against the 
inclusion of articles between the two reviewers was resolved by consensus or the third reviewer $(\mathrm{BF})$.

A second reviewer $(\mathrm{KD})$ was blinded to the primary reviewer's (DA) decision for checking articles selection and data extraction. Any differences of opinion were discussed; otherwise, a third reviewer (BF) was available to arbitrate any issues that remained unresolved.

\section{Data charting (extraction of the results)}

Two authors (DA and ZA) extract the data and compared the results. Discrepancies were resolved by discussion or the third reviewer made the decision. We extracted the following data from each study: author name, year, country, types of digital health technology use, purpose of applying digital health technology (case detection and/or finding disease management and treatment support), study population, study design, types of neglected tropical diseases, and geographical setting (urban/rural) (Additional file 2 and Table 1).

\section{Collating, summarizing, and reporting}

Based on the methodological framework for scoping reviews [30], we were able to present our narrative account of findings in two ways. First, attention was given to the basic numerical analysis of the extent, and distribution of the studies included in the review. We produced the distribution of geographical locations, residents (setting), types of publications, and electronic technologies used on neglected tropical diseases using tables and graphs. Second, the study findings from the

Table 1 Summary of the main features of the 6 studies included in the scoping review on the applications of electronic technologies for treatment outcome, case detection, and disease management (2012-2018)

\begin{tabular}{ll}
\hline Variable & Frequency (\%) \\
\hline Geographical location & $1(16.7)$ \\
India & $1(16.7)$ \\
Ghana & $2(33.3)$ \\
Tanzania & $1(16.7)$ \\
Both (Malawi and Ghana) & $1(16.7)$ \\
At Africa level (review) & \\
Resident & $2(33.3)$ \\
Rural & $1(16.7)$ \\
Urban & $1(16.7)$ \\
Both & $2(33.3)$ \\
Not specific & \\
Types of publication & $2(33.3)$ \\
Expert review & $3(50)$ \\
Original article & $1(16.7)$ \\
Thesis (unpublished)
\end{tabular}

existing literature were presented using thematic content analysis. Our narrative literature was then structured around the themes derived from the study results or outcomes. The themes that emerged from the study were types of electronic technologies used, treatment outcome, case identification/detection, disease management, and disease diagnosis of neglected tropical diseases.

\section{Results}

A total of nine hundred ninety-six potentially relevant studies (790 from PubMed, 96 from Google scholar (advanced), 68 from science direct, 32 from Google,10 from CINAHL, and Cochrane library (0) were generated from the initial search. After duplicates were excluded, 890 studies remained. Then, we excluded most of these potentially relevant papers (848-95\%) based on the title $(n=780)$ and abstract $(n=68)$ review. Overall, 42 studies were eligible for full-text screening.

Afterward, 36 studies were excluded due to electronic technologies used for another disease $(n=20)$, studies deal only about mobile technology (like developing mobile technology and deal on mobile web and devices) ( $n=$ 8 ), other technologies for the diagnosis of disease such as radiology, ultrasonography, and computed axial tomography $(n=2)$, and not related to the electronic technologies, for instance, the impact of golf on health, impact of NTDs on socioeconomic, the burden of NTDs, and inadequate health intervention for neglected tropical diseases ( $n=6)$ (Fig. 1).

\section{Characteristics of included studies}

In this review, six studies were originated from India [31], Tanzania [32, 33], Ghana [34, 35], and Malawi [34], and the review was comprised of one cross-sectional study [33], one follow-up study [35], one qualitative study [32], one case study [34], and two from expert reviews $[31,36]$. Out of the six studies, two studies were from the rural setting [34, 35], one study was from urban [33], one study was from both rural and urban [32], and two studies were the setting is not specified $[31,36]$, because they were not primary studies (Table $1)$.

Out of the six studies, two studies were on leishmaniasis [31, 36], three studies were on lymphatic filariasis [33-35], and one was on multiple NTDs (leishmaniasis, lymphatic filariasis, Chagas disease, and dengue fever) [32] (Fig. 2 and Table 2).

The included studies in this review were published between 2012 [31] and 2018 [36] (Fig. 3).

\section{The theme of the study}

The primary focus of the included studies fitted broadly into three key themes, namely: 


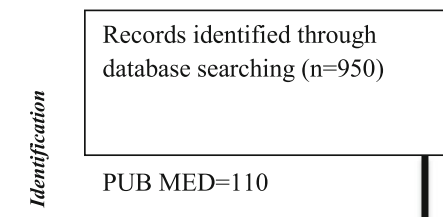

Additional record identified through other sources $(n=46)$
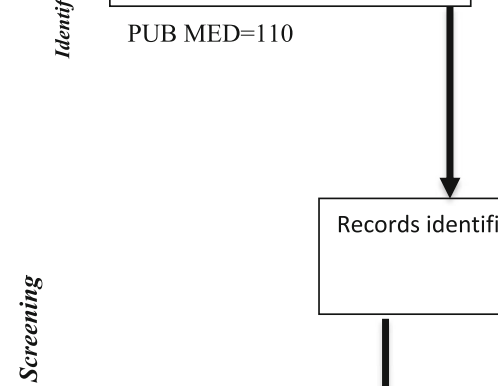

Records identified ( $\mathrm{n}=996$ )

气ัँ
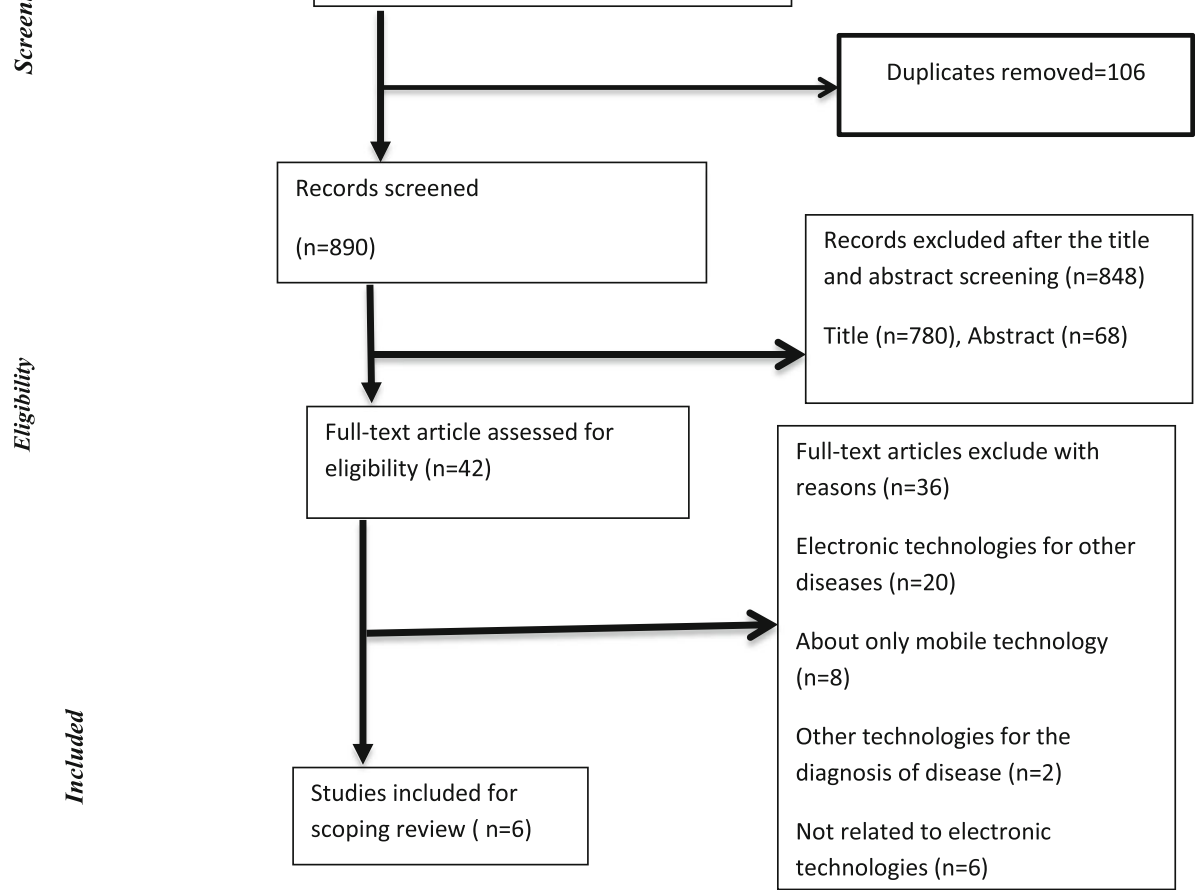

Fig. 1 Flow diagram for the scoping review process adapted from the PRISMA statement by Moher and colleagues (2009)

\section{number of studies}

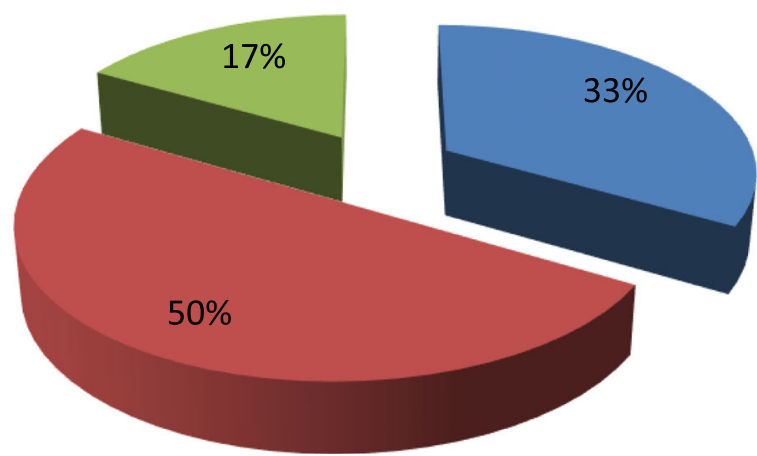

- leishmaniasis

- lyphatic filariasis

All NTDS

Fig. 2 Distribution of included studies by neglected tropical diseases using electronic technologies for treatment support, disease management, case finding, and case detection 
Table 2 Summary of extracted data on the purpose of electronic technology use and their main outcome

\begin{tabular}{|c|c|c|c|c|}
\hline Studies & Types NTDs & $\begin{array}{l}\text { Types of } \\
\text { electronic } \\
\text { technology } \\
\text { use }\end{array}$ & Primary purpose/aim & Main finding \\
\hline $\begin{array}{l}\text { Tambo } \\
\text { et al. }\end{array}$ & Leishmaniasis & $\begin{array}{l}\text { mHealth, } \\
\text { eHealth, and } \\
\text { electronic } \\
\text { health records }\end{array}$ & $\begin{array}{l}\text { Disease management and treatment outcome } \\
\checkmark \text { The use of digital public health technology } \\
\text { applications in understanding and data mapping } \\
\text { models for health and environment decisions, } \\
\text { support in improving health service access, and } \\
\text { uptake in Africa at the community health system }\end{array}$ & [36] \\
\hline $\begin{array}{l}\text { Bhunia } \\
\text { et al. }\end{array}$ & Leishmaniasis & telehealth & $\begin{array}{l}\text { For diagnosis and treatment and vector control } \\
\checkmark \text { To provide a good opportunity for the patients } \\
\text { to have access to remote hospitals for real-time } \\
\text { evaluation by specialists, via either video or audio, } \\
\text { using Doppler and webcams } \\
\checkmark \text { To integrate multifaceted intervention, } \\
\text { prevention, assessment, and treatment to achieve } \\
\text { improved personnel as well as local, national, and } \\
\text { international community health }\end{array}$ & $\begin{array}{l}\text { Improved medical care to remote rural areas, } \\
\text { including many other activities like public } \\
\text { awareness, changing personal behavior, early } \\
\text { diagnosis and complete treatment, integrated } \\
\text { vector management, and vector surveillance; social } \\
\text { mobilization and building partnerships }\end{array}$ \\
\hline $\begin{array}{l}\text { Madon } \\
\text { et al. }\end{array}$ & For all NTDs & $\begin{array}{l}\text { Mobil phone } \\
\text { (SMS) }\end{array}$ & $\begin{array}{l}\text { Control of NTDs (quantifying drug need, } \\
\text { prioritizing disease at the local level, upward } \\
\text { information, and facilitating decision) } \\
\checkmark \text { To test the feasibility of a mobile phone-based } \\
\text { management information system (MIS) using front- } \\
\text { line health workers to capture data at the point of } \\
\text { source for control of NTDs }\end{array}$ & $\begin{array}{l}\checkmark \text { Increase the efficiency of routine work boosting } \\
\text { the motivation and self-esteem of village health } \\
\text { worker } \\
\checkmark \text { Increased the flow of communication with } \\
\text { district-level health official; increase the overall suc- } \\
\text { cess of the NTD control program in the country }\end{array}$ \\
\hline $\begin{array}{l}\text { Vroom } \\
\text { et al. }\end{array}$ & $\begin{array}{l}\text { Lymphatic } \\
\text { filariasis }\end{array}$ & mHealth & Disease management and disease control & $\begin{array}{l}\text { The use of mobile phones does not guarantee } \\
\text { improved data accuracy. However, the type of } \\
\text { mobile technology used may aid in improving } \\
\text { data completeness }\end{array}$ \\
\hline $\begin{array}{l}\text { Mwingira } \\
\text { et al. }\end{array}$ & $\begin{array}{l}\text { Lymphatic } \\
\text { filariasis }\end{array}$ & mHealth & $\begin{array}{l}\text { Case detection } \\
\checkmark \text { Lymphatic filariasis patient identification }\end{array}$ & $\begin{array}{l}\text { The approach is a feasible framework that could } \\
\text { be used in other large urban environments in the } \\
\text { LF endemic areas }\end{array}$ \\
\hline $\begin{array}{l}\text { Stanton } \\
\text { et al. }\end{array}$ & $\begin{array}{l}\text { Lymphatic } \\
\text { filariasis }\end{array}$ & $\begin{array}{l}\text { Mobile message } \\
\text { (SMS) }\end{array}$ & $\begin{array}{l}\text { Case management/disease management } \\
\checkmark \text { To develop and test an SMS tool (measure SMS) } \\
\text { which enables trained community-based health } \\
\text { workers to report basic information on all cases } \\
\text { they identified }\end{array}$ & $\begin{array}{l}\checkmark \text { Enabled national programs to more effectively } \\
\text { monitor their community impact in an efficient, } \\
\text { timely, and cost-effective way. Despite that there } \\
\text { were minor issues such as the quality of their mo- } \\
\text { bile phone, occasional poor network coverage had } \\
\text { little effect on the quality of the data received }\end{array}$ \\
\hline
\end{tabular}

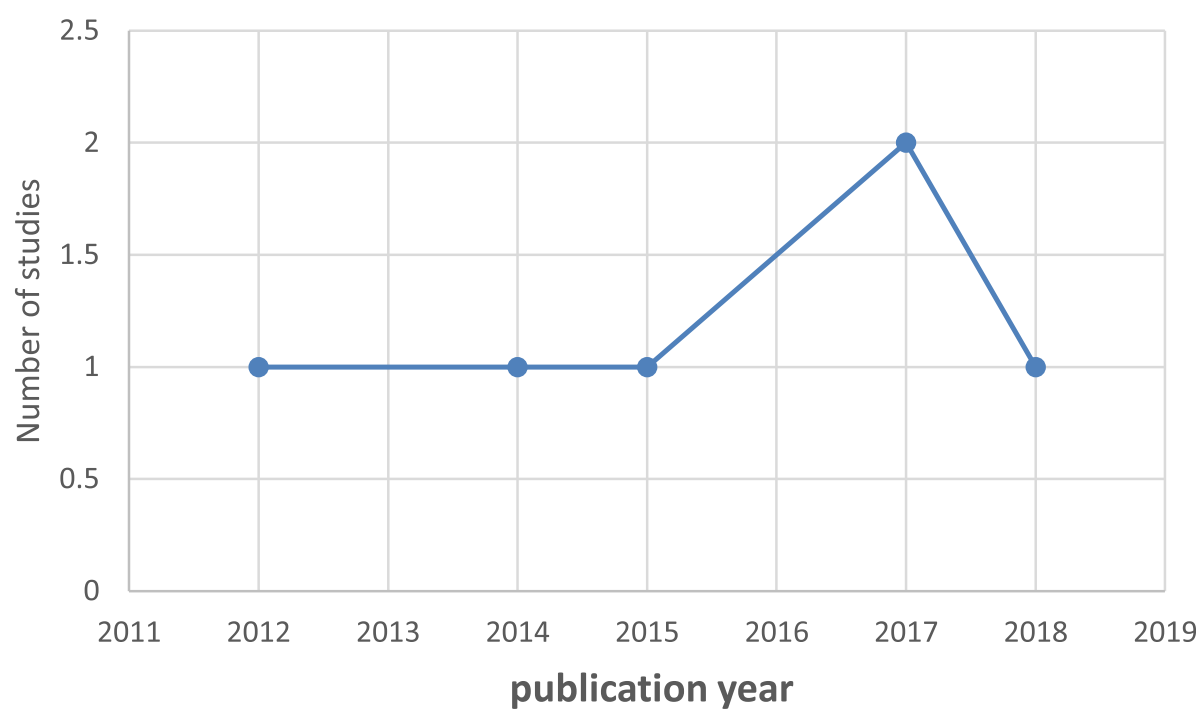

Fig. 3 Number of published studies on neglected tropical diseases using electronic technology per year 
1. Case detection

2. Disease management

3. Treatment outcome

\section{Role of digital health technologies for case detection}

From all included studies, only one study reported on the use of digital health technology for case detection/ identification [33]. Mobile health (mHealth) was deployed for lymphatic filariasis patient identification. The study revealed that the mHealth approach was a feasible framework that can be applied for endemic lymphatic filariasis areas.

\section{Digital health technologies for disease management}

Out of all included studies, electronic technologies were applied to three studies for disease management purposes. mHealth, eHealth, and electronic health records were for visceral leishmaniasis management [36], and mHealth [35], and mobile message [34] were applied for lymphatic disease management. Experts review by Tambo et al. in Africa [36] revealed that using digital public health technology applications support in improving health service delivery or access and uptake in Africa at the community-health system for managing visceral leishmaniasis. Similarly, a case study in Ghana and Malawi [34] directed that use of mobile messages (SMS) enables trained community-based health workers to report basic information on all cases they identified that enables national programs to more effectively monitor their community impact in an efficient, timely, and costeffective way. On the other hand, a study in Ghana in 2017 showed that the use of mobile phones is not a guarantee to improve data accuracy, rather the type of mobile technology used may aid in improving data completeness for treatment support [35].

Only one study was used-telehealth for disease diagnosis [31]. An expert review by Bhunia et al. in India directed that telehealth technology can be used for treatment and diagnosis of visceral leishmaniasis through contact with health professionals and teleconsultation.

\section{The role of digital health technologies for treatment outcome of neglected tropical disease patients}

Only one study revealed the use of electronic technology for neglected tropical disease treatment outcomes. The study was an expert review which showed that the use of mHealth, eHealth, and electronic health records found to improve the service access/delivery and outcomes, monitoring visceral leishmaniasis at the community health system [36].

\section{Discussion}

We conducted a systematic scoping review of studies to explore evidence on electronic technologies used for neglected tropical diseases treatment outcome, case detection, disease management, and disease diagnosis. This study reviewed 10 out of the 20 NTDs identified by the WHO as the most important which have specific drugs for treatment and most commonly found in low- and middle-income countries of Africa, Asia, and Latin America [37].

The findings illustrated that there is limited published research on the use of electronic technologies for neglected tropical diseases treatment outcome, disease management, case detection, and diagnosis. The major findings were reported only for two NTDs (leishmaniasis and lymphatic filariasis) and one reviewed study had information on NTDs in general. In the current review, we observed that there is no increment of studies related to the use of telemedicine and telehealth on NTDs through time. This indicates that there is a need for immediate action from responsible stakeholders to facilitate the application of technologies to reduce the burden of the disease and to achieve a $90 \%$ reduction in the number of people requiring interventions against NTDs by 2030, especially for those hard to reach areas [3].

Even though limited studies were reviewed on a few NTDs, the results from reviewed studies demonstrated that the application or intervention of electronic technologies enhances treatment outcome, disease management, case detection, and disease diagnosis of neglected tropical disease for hard to reach and poor health service access areas. Furthermore, other studies conducted on the improvement of disease management and treatment outcome of infectious and chronic disease using electronic technologies $[20,38]$. These digital health technologies also have indirect effect by updating timely information, and optimizing transportation network to manage the NTDs. Within the era of digital health, a new source of information such as web searches generated data or social media updates, are emerging as a new promising approach in surveillance, and decisionmaking support for NTDs [39, 40].

A study done in Africa on leishmaniasis indicates that using mHealth, eHealth, and electronic health records support improving health service access and uptake in Africa at the community health system that able to improve the service delivery and outcomes, and monitoring visceral leishmaniasis [36]. Additionally, a study conducted in India using telehealth on leishmaniasis established that the digital technology facilitates for disease diagnosis, treatment, and vector control. This finding potentially might help to improve medical care in remote rural areas, including many other activities like public awareness, changing personal behavior, early 
diagnosis and complete treatment, integrated vector management and vector surveillance, social mobilization, and building partnerships [31, 41, 42].

A qualitative study in Tanzania on leishmaniasis, lymphatic filariasis, Chagas disease, and dengue fever in both rural and urban areas revealed that the application of mobile phone-based management information system (MIS) facilitates to control NTDs by quantifying drug need, prioritizing disease at the local level, up warding information for front line health workers in the country. This finding potentially could help treatment outcome and disease management of NTDs for the rest of the African countries and other low- and middle-income countries (LMIC) [43, 44]. Similarly, a study in Ghana and Malawi using mobile message (SMS) on lymphatic filariasis established that using a developed SMS tool enables trained community-based health workers to report basic information on all cases they identified [34]. On the other hand, the finding revealed that there are some problems such as quality of personal mobile phone and occasional poor network coverage that affects the quality data received.

\section{Limitation of the review}

Including studies conducted in both rural and urban settings which provide an overview of digital health technologies on case detection, disease management, and treatment outcome of neglected tropical diseases in the world-the strength of the study. To the best of our knowledge, this is the first comprehensive review in the world to see the sights of electronic technologies to improve NTDs treatment outcome, case detection, disease diagnosis, and management. The other strength of this review was incorporating any types of study design, and expertise review as inclusion criteria and removal of limitation of language and date studies. However, our review has the following limitations: Scoping reviews are broad and provide an overview of existing literature regardless of quality, providing a broader and more contextual overview than systematic reviews. A formal assessment of methodological quality is neither undertaken when conducting a scoping review and synthesis of the incorporating studies nor is the demonstration of a cause and effect nature for the found relationships not possible due to the nature of the included study were another possible limitation.

\section{Conclusion}

This scoping review found that there were limitations of studies on NTDs intervention using digital health technologies that increase the overall success of the NTD control program in low- and middle-income countries especially areas hard to reach and poor availability of health service delivery. The review also found that digital health technologies were applied to limited numbers of NTDs in a very small number of countries.

The current scoping review showed that using digital public health technology applications like mHealth, eHealth, electronic medical linkage, telemed, and telehealth were feasible for patient identification, for treatment and diagnosis through contact with health professionals and teleconsultation, and support in improving health service delivery at the community-health system for managing the disease.

\section{Recommendation for future research}

This review study revealed that there are limited published researches on the use of electronic technologies for treatment outcome, disease management, case finding, and detection of neglected tropical diseases. Even the limited published researches were conducted on very few NTDs. Therefore, we recommended that more primary studies could be conducted in all types of NTDs to get more evidence and to examine the use of electronic technologies for treatment, management case finding, and detection. The review also showed that mobile phone messages/reminders, electronic medical records, and eHealth were used to improve disease management and treatment outcome. Finally, we recommended that experimental study designs using different digital health technologies for case detections, disease management, and treatment outcome of NTDs could be conducted.

\section{Supplementary Information}

The online version contains supplementary material available at https://doi. org/10.1186/s41182-021-00307-1.

Additional file 1:. Keywords included in the search strategy for PubMed databases; terms searched for in the title and abstract of papers.

Additional file 2:. Extracted data.

\begin{abstract}
Abbreviations
JBI: Joanna Briggs Institute; NTD: Neglected tropical diseases; PRISMAScR: Preferred Reporting Items for Systematic reviews and Meta-Analyses extension for Scoping Reviews; WHO: World health organization
\end{abstract}

\section{Acknowledgements}

None.

\section{Authors' contributions}

BT and DA designed the study, reviewed literature, selecting the study, extracted and analyzed data, interpreted results, drafted the manuscript, and reviewing the manuscript for its scientific content. $K D, Z A$, and $B F$ design the study, drafted the manuscript, and reviewing the manuscript for its scientific content. All authors have read and approved the manuscript.

\section{Funding}

This work received funding from the Coalition for Operational Research on Neglected Tropical Diseases (COR-NTD), which is funded at the Task Force for Global Health primarily by the Bill \& Melinda Gates Foundation, by the UK aid from the British government, and by the U.S. Agency for International Development through its Neglected Tropical Diseases Program. 


\section{Availability of data and materials}

The datasets supporting the conclusions of this article are included in the review.

\section{Ethics approval and consent to participate} Not applicable.

\section{Consent for publication}

Not applicable.

\section{Competing interests}

No competing interest.

\section{Author details}

'Department of Health Informatics, Institute of Public Health, College of Medicine and Health Sciences, University of Gondar, Gondar, Ethiopia. ${ }^{2}$ Health System Directorate, Ministry of Health, Addis Ababa, Ethiopia. ${ }^{3}$ Department of Epidemiology and Biostatistics, Institute of Public Health, College of Medicine and Health Science, University of Gondar, Gondar, Ethiopia.

\section{Received: 7 September 2020 Accepted: 10 February 202} Published online: 22 February 2021

\section{References}

1. Hotez PJ, Molyneux DH, Fenwick A, Kumaresan J, Sachs SE, Sachs JD, et al. Control of neglected tropical diseases. New England J Med. 2007;357(10): 1018-27.

2. World Health Organization. Defeating neglecting tropical diseases, progress challenges and opportunities. Geneva; 2020. https://www.who.int/ neglected_diseases/resources/who-cds-ntd-2019.01/en/.

3. World Health Organization. Ending the neglect to attain the sustainable development goals: a road map for neglected tropical diseases 2021-2030. Geneva: World Health Organization; 2020

4. Herrera JS, Franco-Paredes C, Santos-Preciado Jl. The global burden of neglected tropical diseases. Boletín Médico del Hospital Infantil de México. 2011;68(2):78-82.

5. Martins-Melo FR, Ramos AN Jr, Alencar CH, Heukelbach J. Mortality from neglected tropical diseases in Brazil, 2000-2011. Bull World Health Organ. 2016:94(2):103

6. Relman DA, Choffnes ER. The causes and impacts of neglected tropical and zoonotic diseases: opportunities for integrated intervention strategies: National Academies Press; 2011.

7. World Health Organization. Working to overcome the global impact of neglected tropical diseases. France; 2010. https://www.who.int/neglected_ diseases/resources/9789241564090/en/.

8. Garchitorena A, Ngonghala CN, Guegan JF, Texier G, Bellanger M, Bonds M, et al. Economic inequality caused by feedbacks between poverty and the dynamics of a rare tropical disease: the case of Buruli ulcer in sub-Saharan Africa. Proc Biol Sci. 2015;282(1818):20151426.

9. Gunawardena K, Adenowo AF, Oyinloye BE, Ogunyinka BI, Kappo AP. Impact of human schistosomiasis in sub-Saharan Africa. BioMed Res Int. 2015;19(2): 196-205.

10. Turner HC, Bettis AA, Chu BK, McFarland DA, Hooper PJ, Ottesen EA, et al. The health and economic benefits of the global programme to eliminate lymphatic filariasis (2000-2014). Infect Dis Poverty. 2016;5(1):54.

11. Utzinger J, Raso G, Brooker S, De Savigny D, Tanner M, Ornbjerg N, et al. Schistosomiasis and neglected tropical diseases: towards integrated and sustainable control and a word of caution. Parasitology. 2009;136(13):185974

12. Wijerathna T, Gunathilaka N. The economic impact of cutaneous leishmaniasis in Sri Lanka. Biomed Res Int. 2018:2018:3025185.

13. Bhutta ZA, Sommerfeld J, Lassi ZS, Salam RA, Das JK. Global burden, distribution, and interventions for infectious diseases of poverty. Infect Dis Poverty. 2014:3:21

14. Engels D, Zhou XN. Neglected tropical diseases: an effective global response to local poverty-related disease priorities. Infect Dis Poverty. 2020; 9(1):10.

15. Lemoine JF, Desormeaux AM, Monestime F, Fayette CR, Desir L, Direny AN, et al. Controlling neglected tropical diseases (NTDs) in Haiti: implementation strategies and evidence of their success. PLoS Negl Trop Dis. 2016;10(10): e0004954.

16. Checkley W, Ghannem H, Irazola V, Kimaiyo S, Levitt NS, Miranda JJ, et al. Management of NCD in low-and middle-income countries. Global Heart. 2014:9(4):431-43.

17. National Academies of Sciences $E$, and Medicine. Global health and the future role of the United States. Washington DC; 2017.

18. World Health Organization. Working to overcome the global impact of neglected tropical diseases: first WHO report on neglected tropical diseases. World Health Organization; 2010. https://apps.who.int/iris/handle/1 0665/44440.

19. Kelly C, Kamil-Thomas Z. Digital health technologies: digital innovations in public health. Good Health Well-Being. 2020. p. 119-30. https://link.springer. com/10.1007/978-3-319-95681-7_70.

20. Hamine S, Gerth-Guyette E, Faulx D, Green B, Ginsburg A. Impact of mHealth chronic disease management on treatment adherence and patient outcomes: a systematic review. J Med Internet Res. 2015;17:e52.

21. Piette JD, Lun KC, Moura LA Jr, Fraser HS, Mechael PN, Powell J, et al. Impacts of e-health on the outcomes of care in low- and middle-income countries: where do we go from here? Bull World Health Organ. 2012;90(5): 365-72.

22. Dixon BE, Samarth A. Innovations in using health IT for chronic disease management: findings from the AHRQ Health IT Portfolio; 2009.

23. Agency for healthcare research and quality. Chronic disease managment. 2008

24. Parmar P, Mackie D, Varghese S, Cooper C. Use of telemedicine technologies in the management of infectious diseases: a review. Clin Infect Dis. 2015:60(7):1084-94.

25. Young JD, Badowski ME. Telehealth: increasing access to high quality care by expanding the role of technology in correctional medicine. J Clin Med. 2017:6(2):20

26. Pouramin P, Li CS, Busse JW, Sprague S, Devereaux P, Jagnoor J, et al. Delays in hospital admissions in patients with fractures across 18 lowincome and middle-income countries (INORMUS): a prospective observational study. Lancet Global Health. 2020;8(5):e711-e20.

27. Ritchie LMP, Khan S, Moore JE, Timmings C, van Lettow M, Vogel JP, et al. Low-and middle-income countries face many common barriers to implementation of maternal health evidence products. J Clin Epidemiol. 2016;76:229-37.

28. Peters M, Godfrey C, Khalil H, McInerney P, Soares C, Parker D. Guidance for the conduct of JBI scoping reviews., vol. 2017; 2017.

29. Tricco AC, Lillie E, Zarin W, O'Brien KK, Colquhoun H, Levac D, et al. PRISMA extension for scoping reviews (PRISMA-SCR): checklist and explanation. Ann Intern Med. 2018;169(7):467-73.

30. Arksey H, O'Malley L. Scoping studies: towards a methodological framework. Int J Soc Res Methodol. 2005;8(1):19-32.

31. Bhunia GS, Kesari S, Chatterjee N, Kumar V, Das P. Telehealth: a perspective approach for visceral leishmaniasis (kala-azar) control in India. Pathog Global Health. 2012:106(3):150-8.

32. Madon S, Amaguru JO, Malecela MN, Michael E. Can mobile phones help control neglected tropical diseases? Experiences from Tanzania. Soc Sci Med. 2014;102:103-10

33. Mwingira U, Chikawe M, Mandara WL, Mableson HE, Uisso C, Mremi I, et al. Lymphatic filariasis patient identification in a large urban area of Tanzania: an application of a community-led mHealth system. PLoS Negl Trop Dis. 2017;11(7):e0005748

34. Stanton MC, Mkwanda SZ, Debrah AY, Batsa L, Biritwum NK, Hoerauf A, et al. Developing a community-led SMS reporting tool for the rapid assessment of lymphatic filariasis morbidity burden: case studies from Malawi and Ghana. PLoS Negl Trop Dis. 2015;15:214.

35. Vroom F. Feasibility of mobile health for treatment coverage reporting: Iymphatic filariasis control programme in Ghana: University Of Ghana; 2017.

36. Tambo E, Xia S, Xin-Yu F, Xiao-Nong Z. Digital surveillance and communication strat-effigies to infectious diseases of poverty control and elimination in Africa. J Infect Dis Epidemiol. 2018;4:056.

37. World Health Organization. Summary of neglected tropical disease 2020 [cited 2020]

38. Subbaraman $\mathrm{R}$, de Mondesert $\mathrm{L}$, Musiimenta A, Pai M, Mayer KH, Thomas BE, et al. Digital adherence technologies for the management of tuberculosis therapy: mapping the landscape and research priorities. BMJ Global Health. 2018;3(5):e001018 
39. Moro Visconti R, Morea D. Healthcare digitalization and pay-for-performance incentives in smart hospital project financing. International journal of environmental research and public health. 2020;17(7):2318.

40. Gianfredi V, Bragazzi NL, Nucci D, Martini M, Rosselli R, Minelli L, et al. Harnessing big data for communicable tropical and sub-tropical disorders: implications from a systematic review of the literature. Front Public Health. 2018;6:90.

41. Wang $X$, Zhang Z, Zhao J, Shi Y. Impact of telemedicine on healthcare service system considering patients' choice. Discrete Dynamics Nature Soc. 2019;2019.

42. Salisbury C, Thomas C, O'Cathain A, Rogers A, Pope C, Yardley L, et al. TElehealth in cHronic disease: mixed-methods study to develop the TECH conceptual model for intervention design and evaluation. BMJ Open. 2015; 5(2):e006448.

43. Granger BB, Bosworth HB. Medication adherence: emerging use of technology. Curr Opin in Cardiol. 2011;26(4):279-87.

44. Mitchell M, Hedt-Gauthier BL, Msellemu D, Nkaka M, Lesh N. Using electronic technology to improve clinical care - results from a before-after cluster trial to evaluate assessment and classification of sick children according to integrated management of childhood illness (IMCI) protocol in Tanzania. BMC Med Inform Decis Mak. 2013;13:95.

\section{Publisher's Note}

Springer Nature remains neutral with regard to jurisdictional claims in published maps and institutional affiliations.

Ready to submit your research? Choose BMC and benefit from:

- fast, convenient online submission

- thorough peer review by experienced researchers in your field

- rapid publication on acceptance

- support for research data, including large and complex data types

- gold Open Access which fosters wider collaboration and increased citations

- maximum visibility for your research: over $100 \mathrm{M}$ website views per year

At $\mathrm{BMC}$, research is always in progress.

Learn more biomedcentral.com/submissions 